Research Article

\title{
Malignancies and Pediatric Liver Transplantation: Promising Management with the mTOR-inhibitor Everolimus
}

M Wehming ${ }^{1}$, A Briem-Richter ${ }^{1}$, R Ganschow ${ }^{2}$, F Brinkert ${ }^{1}$, B Winkler ${ }^{3}$, L Fischer ${ }^{4}$, E Grabhorn ${ }^{1,}{ }^{*}$

1. Pediatric Gastroenterology and Hepatology, Department of Pediatrics, University Medical Center Hamburg-Eppendorf, Hamburg, Germany; E-Mails: Mathis.wehming@gmx.de; a.richter@uke.de; brinkert@kinderaerzte-weidenallee.de; e.grabhorn@uke.de

2. Department of Pediatrics, University Hospital Bonn, Germany; E-Mail: Rainer.Ganschow@ukb.uni-bonn.de

3. Department of Pediatric Oncology, University Medical Center Hamburg-Eppendorf, Hamburg, Germany; E-Mail: b.winkler@uke.de

4. Department of Hepatobiliary Surgery and Visceral Transplantation, University Medical Center Hamburg-Eppendorf, Hamburg, Germany; E-Mail: I.fischer@uke.de

* Correspondence: E Grabhorn; E-Mail: e.grabhorn@uke.de

Academic Editor: Yasuhiko Sugawara

Special Issue: $\underline{\text { Pediatric Liver Transplantation }}$

OBM Transplantation

2021, volume 5, issue 1

doi:10.21926/obm.transplant. 2101135
Received: June 07, 2020

Accepted: December 31, 2020

Published: January 25, 2021

\begin{abstract}
Some malignancies such as hepatoblastoma may be an indication for liver transplantation (LT) or some, for example, post-transplant lymphoproliferative disease (PTLD) may develop after successful LT. An immunosuppressive therapy after LT can promote the recurrence of the primary malignancy. The mammalian target-of-rapamycin inhibitors (mTORi) are immunosuppressive agents with anti-tumor properties. We examined the impact of everolimus (EVL) together with calcineurin inhibitors on allograft outcome and patient survival in pediatric LT (PLT) with various tumors. This retrospective study included eleven livertransplanted pediatric patients who received EVL after LT. The reason for adding an mTOR inhibitor was the neoplastic disease, either leading to LT $(n=7)$ or PTLD that developed after
\end{abstract}

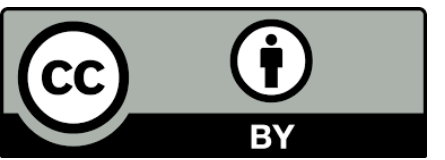

(c) 2021 by the author. This is an open access article distributed under the conditions of the Creative Commons by Attribution License, which permits unrestricted use, distribution, and reproduction in any medium or format, provided the original work is correctly cited. 
LT under immunosuppression $(n=3)$. The median age at the start of therapy was four years (range: seven months- 18 years); the median follow-up was 3 (range: $1-5$ ) years). The primary endpoints were recurrence or metastasis of the primary tumor, uncontrolled PTLD, or death. Graft function and potential side effects were documented. Both patient survival and graft survival rates for the observation period were $100 \%$. No patient developed recurrence or reported metastatic disease of the primary tumor. Liver function test results remained normal during the study period in 8 out of 11 patients. Three patients developed elevated liver enzymes that resolved over time. All the patients received EVL either as monotherapy $(n=2)$ or in combination with cyclosporine $A(n=7)$ or tacrolimus $(n=2)$. Typical side effects documented were recurrent infections $(n=8)$, stomatitis $(n=5)$, and cytopenia $(n=2)$, and medication was temporarily interrupted in one patient. Although the patient cohort was small, our results support the use of EVL in patients with tumor occurrence in the context of pediatric LT. No cases of recurrence or metastases were reported during the follow-up period after LT; sufficient immunosuppression was maintained. The side effect profile appeared acceptable. A longer follow-up in more number of patients is necessary to confirm these preliminary data.

\section{Keywords}

Tumor, pediatric liver transplantation, everolimus, post-transplant lymphoproliferative disease

\section{Introduction}

Liver transplantation (LT) is the standard of care for pediatric patients with end-stage liver disease. Malignant diseases may be an indication for LT or may develop after successful LT, such as a posttransplant lymphoproliferative disease (PTLD). Lifelong immunosuppressive medication is required in order to prevent or control organ rejection. Most of the immunosuppressive regimes after LT are based on calcineurin inhibitors (CNIs) and include concomitant immunosuppressive drugs such as steroids, azathioprine, or mycophenolate mofetil (MMF). Two mTORi, sirolimus and everolimus $(E V L)$, are anti-proliferative immunosuppressive drugs. EVL is a derivative of sirolimus (rapamycin). Typical side effects are infections, cytopenia, hyperlipidemia, local peripheral edema, aphthous ulceration, angioedema, wound healing disorders and proteinuria [1].

Data on adult LT transplantation are promising and show that EVL can maintain graft function in de novo and maintenance liver [2-4], kidney [5], and heart [6] transplant recipients while improving or preserving renal function. Due to the synergism of CNIs and mTORi, the dosage of CNIs can be remarkably reduced $[7,8]$ and may be protective in case of malignancy without increasing the risk of allograft rejection. Data on the use of EVL in pediatric solid organ transplantation are promising but are limited $[9,10]$.

Initial attempts to evaluate the anti-proliferative effect of mTORi showed encouraging results in various adult studies on the recurrence of hepatocellular carcinoma (HCC) after LT [11], malignancies after heart [12] and kidney transplantation [13], renal cell carcinoma [14], and other tumor entities. Studies in pediatric oncological patients are very rare. Various case reports have highlighted the use of EVL for the successful treatment of therapy-resistant Kaposiform hemangioendothelioma $[15,16]$. 
Also, the anti-proliferative effect of mTORi has been demonstrated in the treatment of cerebral giant cell tumors of patients with tuberous sclerosis complex [17-19].

Herein, we present a study on eleven pediatric patients who either received EVL as a primary treatment after LT for malignant disease or switched to EVL due to malignancies in the follow-up period. The aim was to assess the efficacy and safety of EVL in pediatric patients with diagnosed malignancy. EVL was preferred over sirolimus because of its better side effect profile and feasibility of application [20].

\section{Patients and Methods}

This retrospective study included eleven liver-transplanted pediatric patients who had received EVL as an anti-proliferative immunosuppressive drug after LT. A total of 695 pediatric liver transplantations were performed between 1994 and 2014 at our tertiary center (University Medical Center Hamburg- Eppendorf I UKE, University Children's Hospital, Department for Gastroenterology, Hepatology und Liver Transplantation, Martinistr. 52, 20246 Hamburg, Germany). We chose mTORi based on preclinical data showing anti-tumor effects and promising clinical data from adult organ transplant recipients. EVL was introduced if one of the following neoplastic diseases led to LT, or in case of PTLD development after LT under standard immunosuppression: hepatoblastoma (HBL; $\mathrm{n}=$ 3 , one with metastatic disease); PTLD $(n=3)$; hepatocellular tumor of unknown nature with pulmonary metastases $(n=1)$; renal rhabdoid tumor with the veno-occlusive disease $(n=1)$; malignant epithelioid hemangioendothelioma with pulmonary metastases $(n=1)$, human herpesvirus 8 (HHV-8)- induced Kaposi sarcoma after LT and liver transplant failure $(n=1)$ and stage 4 S neuroblastoma (NB) with metastatic liver disease and acute liver failure $(n=1)$.

The median age of LT recipients at the beginning of EVL treatment was four years (range: seven months - 18 years). The median follow-up duration was 3 (range: 1 - 5) years. There were eight de novo liver transplant recipients plus three maintenance patients (time between LT and start of EVL > six months and $\leq$ six months, respectively). Patient data are summarized in Table 1. EVL was used off-label after obtaining prior informed consent of the parents of the patients. 
Table 1 Patient Characteristics.

\begin{tabular}{|c|c|c|c|c|c|c|c|c|c|c|c|c|c|}
\hline patient & sex & $\begin{array}{c}\text { diagnosis leading } \\
\text { to LT }\end{array}$ & $\begin{array}{c}\text { therapy prior to } \\
\text { LT }\end{array}$ & $\begin{array}{l}\text { LT } \\
\text { age }\end{array}$ & $\begin{array}{l}\text { Tx- } \\
\text { Mode }\end{array}$ & $\begin{array}{l}\text { treatment } \\
\text { mode }\end{array}$ & regime & $\begin{array}{l}\text { age at } \\
\text { start } \\
\text { of EVL }\end{array}$ & $\begin{array}{l}\text { follow } \\
\text { up }\end{array}$ & $\begin{array}{c}\text { body } \\
\text { height } \\
\text { (percentile) } \\
\end{array}$ & $\begin{array}{c}\text { body } \\
\text { weight } \\
\text { (percentile) }\end{array}$ & EBV status & CMV status \\
\hline 1 & $\mathrm{~m}$ & $\begin{array}{l}\text { hepatoblastoma } \\
\text { [PRETEXT III] }\end{array}$ & $\mathrm{n} / \mathrm{a}$ & $2 y$ & $\mathrm{pm}-\mathrm{s}$ & d.n. & $\begin{array}{l}\text { EVL/CsA } \\
\text { EVL/Tac }\end{array}$ & $2 y$ & $1 y$ & $\begin{array}{l}86 \mathrm{~cm} \\
(23,6)\end{array}$ & $\begin{array}{l}11 \mathrm{~kg} \\
(9,5)\end{array}$ & $\begin{array}{l}\text { VCA-IgM QL (-) } \\
\text { EA-IgG QL (+) } \\
\text { EBNA-IgG (+) }\end{array}$ & $\begin{array}{l}\operatorname{IgG}-Q \mathrm{Q}(+) \\
\operatorname{IgM} Q \mathrm{QL}(-)\end{array}$ \\
\hline 2 & $\mathrm{~m}$ & $\begin{array}{l}\text { hepatoblastoma } \\
\text { [PRETEXT III] }\end{array}$ & $\begin{array}{l}\text { IPA; R0-resection; IPA; } \\
\text { TR: bvzb/it; } 2 \times C E ; \text { RO- } \\
\text { resection }\end{array}$ & $15 y$ & $\mathrm{pm}-\mathrm{s}$ & d.n. & $\mathrm{EVL} / \mathrm{CsA}$ & $15 y$ & $3 y$ & $\begin{array}{c}156 \mathrm{~cm} \\
(1,7)\end{array}$ & $\begin{array}{l}39 \mathrm{~kg} \\
(<1)\end{array}$ & $\begin{array}{l}\text { VCA-IgM QL (-) } \\
\text { EA-IgG QL (+) } \\
\text { EBNA-IgG (+) }\end{array}$ & $\begin{array}{c}\operatorname{IgG} \text { QL (+) } \\
\operatorname{IgM}-\mathrm{QL}(-) \\
\operatorname{pp65} \text { AG (-) } \\
\text { PCR (-) }\end{array}$ \\
\hline 3 & $f$ & $\begin{array}{c}\text { malignant rhabdoid } \\
\text { tumor [initial suspicion } \\
\text { of nephroblastoma } \\
\text { Stadium III, LN(+)] + } \\
\text { VOD/ALF }\end{array}$ & $\begin{array}{c}\text { VCR/Act-D; } \\
\text { tumor nephrectomy; } \\
\text { CTx acc. to EuRhab } \\
\text { Reg }\end{array}$ & $1 y$ & $\mathrm{pm}-\mathrm{s}$ & d.n. & $\mathrm{EVL} / \mathrm{CsA}$ & $1 y$ & $1 y$ & $\begin{array}{l}74 \mathrm{~cm} \\
(33,7)\end{array}$ & $\begin{array}{c}9 \mathrm{~kg} \\
(36.7)\end{array}$ & $\begin{array}{c}\text { VCA-IgM QL (-) } \\
\text { EA-IgG QL (+) } \\
\text { EBNA-IgG + PCR } \\
(-)\end{array}$ & $\begin{array}{l}\operatorname{IgG}-\mathrm{QL}(+) \\
\operatorname{IgM} Q \mathrm{QL}(-) \\
\text { PCR (-) }\end{array}$ \\
\hline 4 & $\mathrm{~m}$ & $\begin{array}{c}\text { hepatoblastoma } \\
\text { [Stad IV, PRETEXT III, } \\
\text { M+ (pl)] }\end{array}$ & $\begin{array}{c}\text { SIOPEL 3: } \\
\text { CDDP/Cp/Dox; } \\
\text { hemihepatectomy } \\
\text { (ext. left); } \\
\text { CDDP, Cp/Dox; ICE, } \\
\text { It/Vcr }\end{array}$ & $3 y$ & pm-s & d.n. & $\mathrm{EVL} / \mathrm{CsA}$ & $3 y$ & $4 y$ & $\begin{array}{l}99 \mathrm{~cm} \\
(69,5)\end{array}$ & $\begin{array}{l}17 \mathrm{~kg} \\
(84,6)\end{array}$ & $\begin{array}{l}\text { VCA-IgM QL (-) } \\
\text { EA-IgG QL (-) } \\
\text { EBNA-IgG (+) } \\
\text { PCR (-) }\end{array}$ & $\begin{array}{l}\operatorname{IgG-QL}(+) \\
\operatorname{IgM} Q L(-) \\
\text { PCR (-) }\end{array}$ \\
\hline 5 & $\mathrm{~m}$ & $\begin{array}{c}\text { undifferentiated } \\
\text { hepatocellular tumor } \\
{[\mathrm{M}+(\mathrm{pl})]}\end{array}$ & $\begin{array}{c}\text { SIOPEL } 4 \text { + Sorafenib } \\
\text { M+(pl)-resection } \\
\text { CTx acc. to HB99 } \\
\text { (Cp/EPEG) }\end{array}$ & $18 y$ & $\mathrm{pm}-\mathrm{fs}$ & d.n. & EVL/Tac & $18 y$ & $2 y$ & $\begin{array}{c}167 \mathrm{~cm} \\
(4)\end{array}$ & $\begin{array}{l}45 \mathrm{~kg} \\
(<1)\end{array}$ & $\begin{array}{c}\text { VCA-IgM QL (-) } \\
\text { EA-IgG QL (+) } \\
\text { EBNA-IgG (+) } \\
\text { PCR (-) }\end{array}$ & $\begin{array}{l}\text { IgG-QL (+) } \\
\text { IgM QL (-) } \\
\text { PCR (-) }\end{array}$ \\
\hline 6 & $\mathrm{~m}$ & $\begin{array}{l}\text { malignant epithelioid } \\
\text { hemangioendothelioma }\end{array}$ & $\begin{array}{l}\text { Celecoxib, Vbl, } \\
\text { Thalidomid }\end{array}$ & $13 y$ & $\mathrm{pm}-\mathrm{s}$ & d.n. & EVL/Tac & $13 y$ & $1 y$ & $\begin{array}{l}158 \mathrm{~cm} \\
(44,4)\end{array}$ & $\begin{array}{l}56 \mathrm{~kg} \\
(72,2)\end{array}$ & $\begin{array}{l}\text { VCA-IgM QL (-) } \\
\text { EA-IgG QL (+) }\end{array}$ & $\begin{array}{l}\operatorname{IgG}-\mathrm{QL}(+) \\
\operatorname{lgM} \mathrm{QL}(+)\end{array}$ \\
\hline
\end{tabular}


of the liver $[\mathrm{M}+(\mathrm{pl})]$

uroblastoma of the
CTx [NB-2004; LR-

$$
\text { Arm, 2xN4] }
$$

$3 m \quad p m-f s$
EBNA-IgG (+) PCR

pp65 AG (-)

gland [Stad IV; M+ (Iv)]

(and $2 \times \mathrm{N}^{2}$

$\mathrm{EVL} / \mathrm{CsA} \quad 7 \mathrm{~m}$

\section{treatment for NPL}

ITx/Tx-associated NPL

CTx acc. to

m biliary atresia / DLBCL

m [CD20 (+); c myc (-)]

PED-PTLD 2005:

$$
\text { Rituximab }
$$

B-NHL 04: A4 und B4

\section{maple syrup urine}

m

disease/polymorphic

PTLD

$E V L+$ reduced CsA

$2 \mathrm{~m}$

$2 \mathrm{~m} \quad \mathrm{pm}-\mathrm{s}$

$\mathrm{mt}$

EVL/CsA

$2 y$

$4 y$

$(14,7)$

$\mathrm{EVL}+$ reduced CsA

PFIC [type I]/HHV-8

induced Kaposi sarcoma

\begin{abstract}
Re-LTX
\end{abstract}
doxorubicin

PED-PTLD 2005:

$11 \mathrm{f}$ biliary atresia/PTLD
EVL, Rituximab

3y Id

1y Id

mComp

Act-D = Actinomycin D; ALV = acute liver failure; bm = bone marrow; Bvzb = Bevacizumab; $C p=$ Carboplatin; CDDP = Cisplatin; CTx = chemotherapy; . $n$. = de novo therapy; DLBCL = diffuse large B-Cell lymphoma; Dox = doxorubicin; EPEG = etoposide; EuRhab Reg = [doxorubicin, ICE (Ifosfamid, Carboplatin, Etoposid), VAC = [vincristine, actinomycin D, cyclophosphamide]; IPA = ifosfamide, cisplatin, doxorubicin; It = irinotecan; Id = living donor; IV = liver; mt = maintenance therapy; $\mathrm{mCOMP}=$ (vincristine, cyclophosphamide, low dose methotrexate, prednisone); $\mathrm{n} / \mathrm{a}=\mathrm{not}$ available; $\mathrm{NPL}=\mathrm{neoplasia;}$ pm-fs = post mortem full size; pm-s = post mortem split; $\mathrm{pl}=$ pulmo; $\mathrm{TR}=$ tumor recurrence; Vbl = Vinblastine; Vcr: vincristine; VOD = Venous occlusive disease 
Primary endpoints for this study were recurrence or metastasis of the primary tumor, uncontrolled PTLD, or death. Graft function (aspartate aminotransferase, ASAT; alanine aminotransferase, ALAT; gamma-glutamyl transferase, $\gamma \mathrm{GT}$; bilirubin), kidney function (creatinine, cystatin C) and possible side effects of the mTORi, as well as of growth factors, were documented. In case of clinical or laboratory signs of graft rejection (such as elevated liver enzymes) or hyperbilirubinemia, a liver biopsy was carried out percutaneously.

\section{Medication}

Standard immunosuppression after LT at our center consisted of the CNI cyclosporine A (CsA; initial trough levels: $150-180 \mu \mathrm{g} / \mathrm{L}$, maintenance levels after one year: 100-120 $\mu \mathrm{g} / \mathrm{L}$ ) or tacrolimus (TAC; initial trough levels: 7-9 $\mu \mathrm{g} / \mathrm{L}$; maintenance levels after one year: $~ 5 \mu \mathrm{g} / \mathrm{L}$ ) and corticosteroids with an initial dose of $15 \mathrm{mg} / \mathrm{m}^{2}$. In most of the cases, the dose of corticosteroids was reduced to 1 $\mathrm{mg} / \mathrm{m}^{2}$ after six months. Corticosteroid medication was usually discontinued after one year. In all patients, the anti-interleukin-2 receptor antibody, basiliximab, was administered in two single doses on day 0 and day 4 post-transplant.

Tumor patients $(n=9)$ were treated with EVL in combination with reduced CNI doses (initial target trough levels for EVL 4-6 $\mu \mathrm{g} / \mathrm{L}$; CsA 80-100 $\mu \mathrm{g} / \mathrm{L}$, maintenance level 40-60 $\mu \mathrm{g} / \mathrm{L}$, TAC maintenance 3-5 $\mu \mathrm{g} / \mathrm{L})$. Two patients with PTLD received EVL monotherapy after chemotherapy.

\section{Results}

Both patient survival and graft survival rates during follow-up were $100 \%$. None of the patients developed recurrence or reported the metastatic spread of the primary tumor. Liver function tests were normal during the study period in seven out of 11 patients, while four(maintenance $n=3$; de novo $n=1)$ patients showed a temporary $(n=3)$ or permanent $(n=1)$ elevation of liver enzymes. In nine patients, a liver biopsy was performed either routinely or due to elevated liver enzymes. Two of three PTLD patients showed signs of acute rejection at low trough levels of EVL. The first patient was initially switched from CSA to TAC immediately after LT due to steroid-resistant rejection. Two years after LT, this patient developed a polymorphic PTLD of the tonsils, and hence he has switched again to low-dose CsA, which also led to recurrent rejection. After adding EVL to CSA, the PTLD regressed, and the extent of rejection decreased over time.

The second patient was administered low-dose monotherapy with EVL (trough levels $3-4 \mu \mathrm{g} / \mathrm{L}$ ) after chemotherapy and developed elevated levels of transaminases with biopsy-confirmed acute rejection (Banff grade score: 3/9), which resolved with taking higher trough levels of EVL about 7$10 \mu \mathrm{g} / \mathrm{L}$. The third patient experienced no transplant rejection episode.

Renal function was monitored on the basis of levels of creatinine and cystatin $C$ and estimated glomerular filtration rate (eGFR). Three patients remained stable $\left( \pm 10 \mathrm{~mL} / \mathrm{min} / 1.73 \mathrm{~m}^{2}\right)$, while in two patients the eGFR improved slightly over time (+11 to $\left.20 \mathrm{~mL} / \mathrm{min} / 1.73 \mathrm{~m}^{2}\right)$. Renal function deteriorated in four patients (maintenance $\mathrm{n}=2$; de novo $\mathrm{n}=2$ ). Two patients recorded considerable decrease of $>20 \mathrm{~mL} / \mathrm{min} / 1.73 \mathrm{~m}^{2}$ while another two recorded an insignificant decrease of $\Delta=-11$ to $-20 \mathrm{~mL} / \mathrm{min} / 1.73 \mathrm{~m}^{2}$ ). In two patients, a cystatin C eGFR was not obtained; creatinine levels remained stable in the normal range. Figure 1 illustrates the GFR, and Figure 2 illustrates GPT levels over time. 


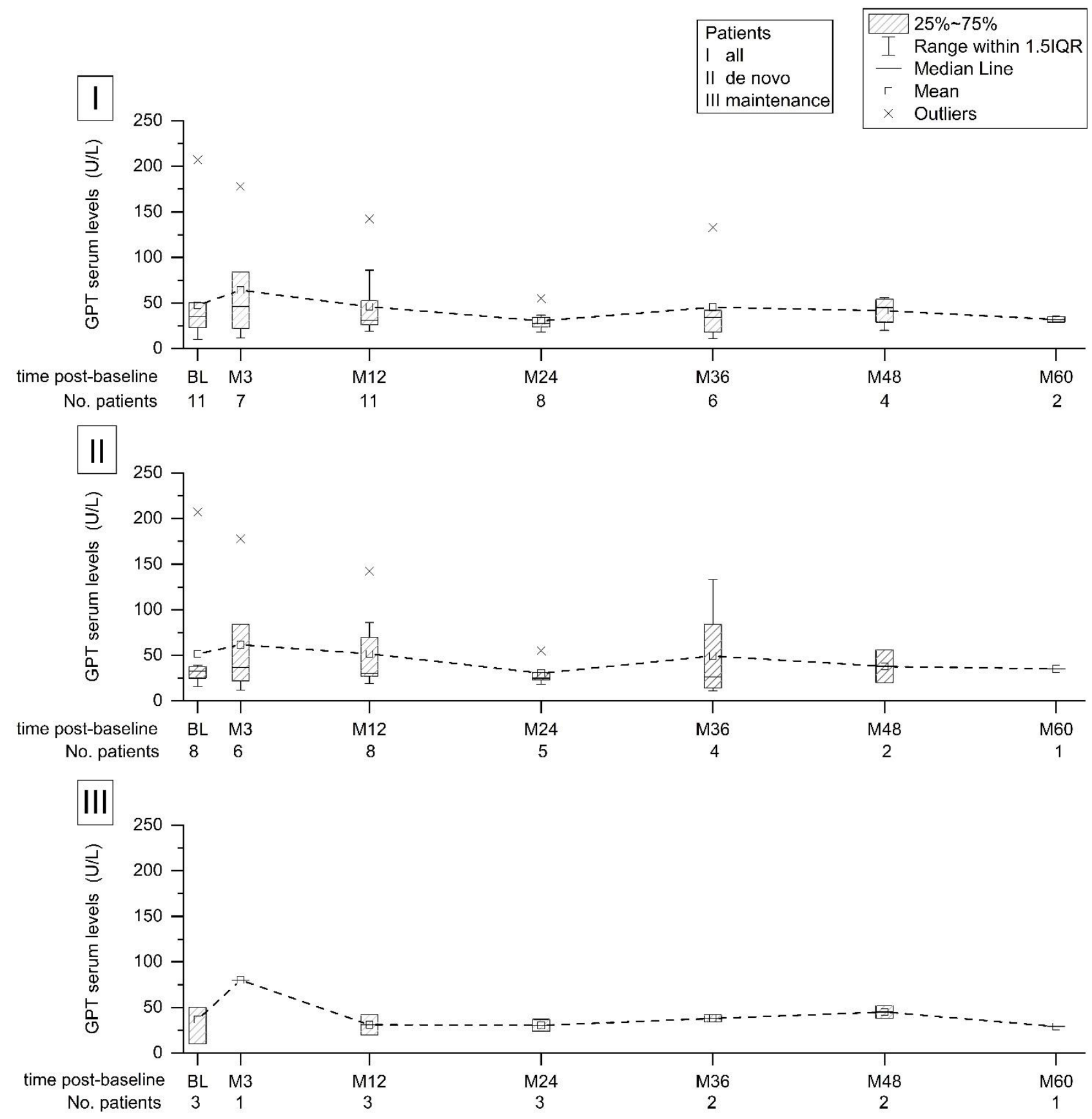

Figure 1 GFR levels over time. 


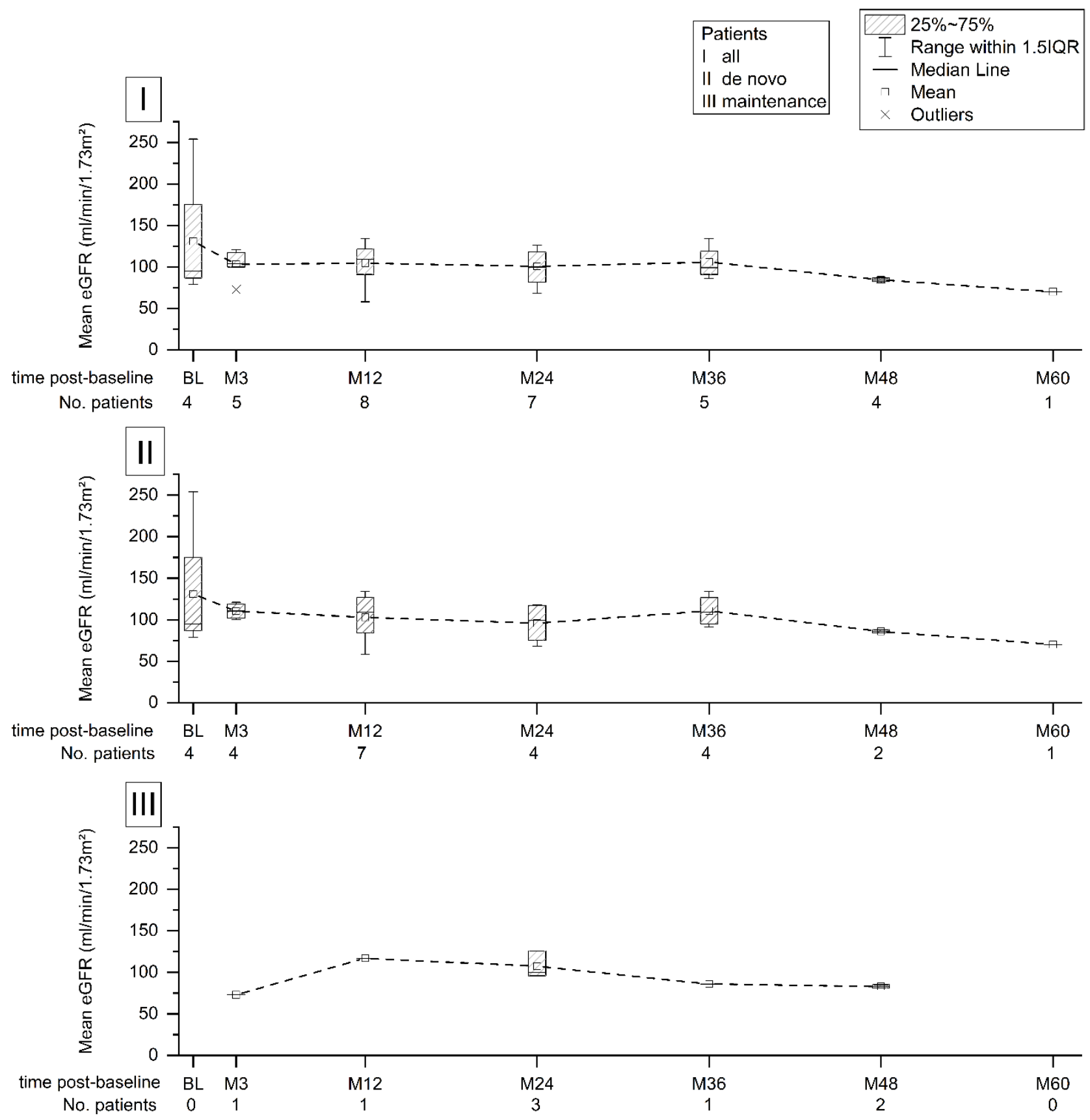

Figure 2 GPT levels over time.

During the observation period, 9 out of 11 patients suffered from various side effects, as summarized in Table 2. Most of the complaints were mild, predominantly upper airway infections ( $\mathrm{n}$ $=8$ ), which were controlled in most cases by symptomatic or antibiotic therapy. In one patient, EVL treatment was discontinued due to recurrent susceptibility to infections. Aphthous lesions were other typical side effects that were observed in five (45\%) patients. Mild hyperlipidemia occurred in one patient. All patients had normal Height and weight development.

Table 2 Side effects.

\begin{tabular}{ll}
\hline bacterial infection, $\mathrm{n}(\%)$ & $8(72.7)$ \\
aphthous mouth ulceration, $\mathrm{n}(\%)$ & $5(45.5)$ \\
cytopenia, $\mathrm{n}(\%)$ & $2(18.2)$ \\
\hline
\end{tabular}




\section{Discussion}

In the current study, we report eleven pediatric LT patients receiving EVL as an anti-proliferative therapy in combination with a low-dose $\mathrm{CNI}$ in the context of various tumors. The logic behind choosing the immunosuppressive regime was to preserve liver graft function while simultaneously minimizing the risk of tumor recurrence or tumor spread after LT.

To date, a limited number of studies are available on the efficacy and tolerance of EVL in the context of oncological diseases and pediatric LT, but there is adequate information available for adult patients. Animal and preclinical studies have shown anti-tumor effects of mTORi [21, 22]. mTORi are already being used as a second-line treatment for renal cell carcinomas [14] as well as for advanced pancreatic neuroendocrine tumors [23] .

Thimonier et al. (2014) compared the survival of patients with de novo malignancies after LT, both under EVL-based and standard immunosuppression[24]. Their findings strongly suggest that conversion to EVL improves the prognosis of these cancers after LT for alcoholic cirrhosis. Cholongitas et al. (2014) performed a systematic review of the association between mTORi and HCC recurrence after LT and compared it with that for CNI-treated patients and concluded that patients under CNIs developed HCC recurrence significantly more frequently than those under mTORi and favored use of mTORi for HCC recurrence post LT [25]. Moreover, Cheung et al. recently investigated the impact of mTORi conversion together with minimization of $\mathrm{CNI}$ on allograft outcome and patient survival in kidney transplant recipients with post-transplant cancers and suggested that this combination is also a reasonable option because of stable renal function, low rejection rate, and low cancer recurrence rate [26].

These treatments cannot directly be adopted for pediatric patients due to differences in metabolism and the underlying entities [27]. There are only sparse data regarding the use of EVL in children with proliferative diseases. Two centers have reported a beneficial course for Kaposiform hemangioendothelioma treated with EVL after failure to respond to prednisolone and vincristine $[15,16]$. mTORi are being increasingly used as treatment options for tuberous sclerosis complex with giant cell tumors of the brain and drug-resistant seizures. Krueger et al. showed impressive results in children over three years of age who were treated for subependymal giant cell astrocytoma (SGCA) and noticed a reduction of tumor volume and in the number of seizures[19]. These findings were corroborated by Kotulska et al. in children under three years of age [17]. The incidence of adverse events was found similar to that observed in older children and adults. The effect of EVL was confirmed even in patients with tumor recurrence after surgical resection for SGCA [18].

None of our eleven patients developed any metastasis or recurrence of the primary tumor during the observation period, and all the patients maintained good graft function. Moreover, no death occurred during the observation period. Overall patient survival and graft survival rates after LT for non-resectable liver malignancies in children were analyzed in several studies. A retrospective study reviewed the outcome of 677 children under 21 years of age after LT for malignancies and reported a diverse 10-year graft survival for different tumor entities (lowest for HCC; 42.7\%). The deaths occurred in $22.6 \%$ of the patients, and the risk of death due to recurrence persisted the longest in HCC and bile duct carcinoma [28]. The follow-up research revealed improvement in the 5-year graft survival rate in the last decade, compared to the previous decade, for $\mathrm{HBL}$ ( $75.1 \%$ versus $82.6 \%$ ) and HCC (60\% versus 81\%)[29]. Pham et al. reported 1-, 5- and 10- year disease-free survival after LT with $93 \%, 82 \%$, and $82 \%$ for 30 patients with $\mathrm{HBL}$ and $90 \%, 78 \%$, and $78 \%$, respectively, for ten patients with HCC [30]. However, none of those studies investigated the influence of different 
immunosuppressant regimes on patient and graft survival. Comparing those results to our results might suggest that treatment with mTORi, mostly in combination with reduced $\mathrm{CNI}$, had a beneficial effect on the outcome, despite the clear limitation of a relatively small cohort population and shorter observations in our study. This assumption is supported by data in adult liver graft recipients for treatment of hepatocellular carcinoma concerning the lower risk of recurrence for reduced dosages of CNI [30-32].

Three patients received EVL due to the development of PTLD. The development of PTLD is mainly associated with primary EBV infection superimposed on LT and sometimes CMV co-infection[33]. The first choice in mild cases is to reduce standard immunosuppression so as to reduce EBV replication and control lymphatic proliferation [34, 35]. One PTLD patient developed a rejection under reduced immunosuppression with CSA; the addition of EVL led to stabilization over time and stable graft function four years after the switch to the new regime. Another PTLD patient was given EVL monotherapy with good control of the PTLD but developed acute rejection due to low trough levels. After increasing the EVL dosage, liver enzymes normalized, and the patient had stable graft function three years after initiation of therapy. Both patients were EBV-seropositive before developing rejection events. The third patient experienced no episodes of LT rejection. These data were supported by results in some case reports using sirolimus as an immunosuppressant in the context of PTLD and LT, and a study by Kusuki et al. on a pediatric post-transplant diffuse large B-cell lymphoma after cardiac transplantation[36-38]. All these patients experienced long-term cures and were maintained with good graft function on a mono- or combination therapy with mTORi and lowdose CsA.

$\mathrm{CNI}$-based immunosuppression is the most common regime in children after LT. CNI-induced nephrotoxicity is one of the prominent side effects leading to impaired renal function in the longterm follow-up[39]. Our group also showed that cystatin $\mathrm{C}$ is a useful marker for kidney dysfunction that enables the identification of a high proportion of liver-transplanted children with renal impairment [40]. Several studies have found an improved renal outcome in pediatric kidney transplantation with mTORi as a de novo treatment [41] as well as conversion from a CNI-based to an sirolimus-based immunosuppressive regime in maintenance patients [42]. Similar results were observed in studies with sirolimus concerning maintenance in recipients of pediatric liver transplants[43]. The renal outcomes of our patients differed in certain findings from these results. Only two patients had an improved GFR, while three patients had a stable GFR. The majority of those cases were reported in de novo graft recipients. Only in one out of three maintenance graft recipients, stabilization of the eGFR was observed. However, serum creatinine level remained within the reference range in all patients, probably because of a particular selection of tumor patients, who had already received considerable quantities of nephrotoxic substances (e.g., chemotherapy) prior to LT. This suggests a higher vulnerability to further renal toxicity. Moreover, long-term preservation of renal function could possibly be achieved more successfully by early reduction of CNI (1-12 months post LT), mostly with simultaneously establishing a concomitant nephroprotective immunosuppressive agent[44]. Possibly, EVL can provide better improvement or maintenance of renal function in some patients than a CNI-based immunosuppressive regime. All immunosuppressive drugs, including mTORi, cause typical side effects, such as increased susceptibility to infections. The most commonly reported drug-related adverse events in a pediatric study with mTORi were infections, mostly of the upper respiratory tract and urinary tract. Recent data on pediatric kidney transplantation also suggest that de novo organ recipients receiving mTORi in combination with low-dose CNI face the risk of developing infections $[41,45]$. In our study, 8 out 
of 11 patients suffered from recurrent bacterial infections. Although this number seems significant, most infections were mild, and only one patient had to discontinue treatment with EVL. We consider this side effect as significant but no more serious than for other immunosuppressive regimes due to EVL manageability.

Infants with an immature immune system may unlikely be ideal candidates for mTORi therapy, but sufficient data are still lacking to reach a conclusive decision on ideal therapy.

Patients treated with EVL are more likely to develop aphthous mouth ulceration than those treated with other immunosuppressants $[3,46,47]$. Although painful and unpleasant, aphthous mouth ulceration usually remains transient and often responds to local treatment and hence does not necessitate discontinuation of EVL medication in our patients.

\section{Conclusion}

Although the study cohort was small, our findings support the use of EVL in patients with tumor occurrence in the context of pediatric LT and immunosuppression. No cases of recurrence and metastatic disease were reported in the follow-up period after LT while maintaining sufficient immunosuppression. In this study, we believe the side effect profile to be acceptable. A longer follow-up is necessary to confirm these results.

\section{Abbreviations}

CNI, calcineurin inhibitors; CSA, cyclosporine A; EVL, Everolimus; HBL, hepatoblastoma; HCC, hepatocellular carcinoma; MFF, mycophenolate mofetil; hepatocellular carcinoma LT, liver transplantation; mTORi, mTOR inhibitor; post-transplant lymphoproliferative disease, PTLD; Tac, Tacrolimus

\section{Author Contributions}

Mathis Wehming: Participated in data collection and data analysis, the writing of the paper; Andrea Briem-Richter: Participated in research design; Rainer Ganschow: Participated in research design; Beate Winkler: Critical revision; Florian Brinkert: Critical revision; Lutz Fischer: Critical revision; Enke Grabhorn: Participated in research design, the writing of the paper, the performance of the research, and in data analysis.

\section{Funding}

The study was supported be Novartis Pharma, Switzerland.

\section{Competing Interests}

The authors of this manuscript have no conflicts of interest to disclose.

\section{References}

1. Kaplan B, Qazi Y, Wellen JR. Strategies for the management of adverse events associated with mTOR inhibitors. Transplant Rev (Orlando). 2014; 28: 126-133.

2. Castroagudin JF, Molina E, Romero R, Otero E, Tome S, Varo E. Improvement of renal function after the switch from a calcineurin inhibitor to everolimus in liver transplant recipients with 
chronic renal dysfunction. Liver Transpl. 2009; 15: 1792-1797.

3. De Simone P, Metselaar HJ, Fischer L, Dumortier J, Boudjema K, Hardwigsen J, et al. Conversion from a calcineurin inhibitor to everolimus therapy in maintenance liver transplant recipients: A prospective, randomized, multicenter trial. Liver Transpl. 2009; 15: 1262-1269.

4. Levy G, Schmidli H, Punch J, Tuttle-Newhall E, Mayer D, Neuhaus P, et al. Safety, tolerability, and efficacy of everolimus in de novo liver transplant recipients: 12 - and 36-month results. Liver Transpl. 2006; 12: 1640-1648.

5. Carmellini M, Garcia V, Wang Z, Vergara M, Russ G. Efficacy of everolimus with reducedexposure cyclosporine in de novo kidney transplant patients at increased risk for efficacy events: Analysis of a randomized trial. J Nephrol. 2015; 28: 633-639.

6. Hirt SW, Bara C, Barten MJ, Deuse T, Doesch AO, Kaczmarek I, et al. Everolimus in heart transplantation: An update. J Transplant. 2013; 2013: 683964.

7. Nashan Br, Curtis J, Ponticelli C, Mourad G, Jaffe J, Haas T. Everolimus and reduced-exposure cyclosporine in de novo renal-transplant recipients: A three-year phase II, randomized, multicenter, open-label study. Transplantation. 2004; 78: 1332-1340.

8. Chan L, Greenstein S, Hardy MA, Hartmann E, Bunnapradist S, Cibrik D, et al. Multicenter, randomized study of the use of everolimus with tacrolimus after renal transplantation demonstrates its effectiveness. Transplantation. 2008; 85: 821-826.

9. Nielsen D, Briem-Richter A, Sornsakrin M, Fischer L, Nashan B, Ganschow R. The use of everolimus in pediatric liver transplant recipients: First experience in a single center. Pediatr Transplant. 2011; 15: 510-514.

10. Brunkhorst LC, Fichtner A, Hocker B, Burmeister G, Ahlenstiel-Grunow T, Krupka K, et al. Efficacy and safety of an everolimus- vs. a mycophenolate mofetil-based regimen in pediatric renal transplant recipients. PLoS One. 2015; 10: e0135439.

11. Duvoux C, Toso C. mTOR inhibitor therapy: Does it prevent HCC recurrence after liver transplantation? Transplant Rev (Orlando). 2015; 29: 168-174.

12. Wang YJ, Chi NH, Chou NK, Huang SC, Wang $\mathrm{CH}$, Wu IH, et al. Malignancy after heart transplantation under everolimus versus mycophenolate mofetil immunosuppression. Transplant Proc. 2016; 48: 969-973.

13. Kauffman HM, Cherikh WS, Cheng Y, Hanto DW, Kahan BD. Maintenance immunosuppression with target-of-rapamycin inhibitors is associated with a reduced incidence of de novo malignancies. Transplantation. 2005; 80: 883-889.

14. Anandappa G, Hollingdale A, Eisen T. Everolimus - a new approach in the treatment of renal cell carcinoma. Cancer Manag Res. 2010; 2: 61-70.

15. Uno T, Ito S, Nakazawa A, Miyazaki O, Mori T, Terashima K. Successful treatment of Kaposiform hemangioendothelioma with everolimus. Pediatr Blood Cancer. 2015; 62: 536-538.

16. Matsumoto H, Ozeki M, Hori T, Kanda K, Kawamoto N, Nagano A, et al. Successful everolimus treatment of kaposiform hemangioendothelioma with Kasabach-Merritt phenomenon: Clinical efficacy and adverse effects of mTOR Inhibitor therapy. J Pediatr Hematol Oncol. 2016; 38: e322e325.

17. Kotulska K, Chmielewski D, Borkowska J, Jurkiewicz E, Kuczynski D, Kmiec T, et al. Long-term effect of everolimus on epilepsy and growth in children under 3 years of age treated for subependymal giant cell astrocytoma associated with tuberous sclerosis complex. Eur J Paediatr Neurol. 2013; 17: 479-485. 
18. Franz DN, Agricola KD, Tudor CA, Krueger DA. Everolimus for tumor recurrence after surgical resection for subependymal giant cell astrocytoma associated with tuberous sclerosis complex. J Child Neurol. 2013; 28: 602-607.

19. Krueger DA, Care MM, Agricola K, Tudor C, Mays M, Franz DN. Everolimus long-term safety and efficacy in subependymal giant cell astrocytoma. Neurology. 2013; 80: 574-580.

20. Yee ML, Tan HH. Use of everolimus in liver transplantation. World J Hepatol. 2017; 9: 990-1000.

21. Majewski M, Korecka M, Joergensen J, Fields L, Kossev P, Schuler W, et al. Immunosuppressive TOR kinase inhibitor everolimus (RAD) suppresses growth of cells derived from posttransplant lymphoproliferative disorder at allograft-protecting doses. Transplantation. 2003; 75: 17101717.

22. Mendes J, Goncalves AC, Alves R, Jorge J, Pires A, Ribeiro A, et al. L744,832 and everolimus induce cytotoxic and cytostatic effects in non-hodgkin lymphoma cells. Pathol Oncol Res. 2016; 22: 301-309.

23. Kulke $\mathrm{MH}$, Bendell J, Kvols L, Picus J, Pommier R, Yao J. Evolving diagnostic and treatment strategies for pancreatic neuroendocrine tumors. J Hematol Oncol. 2011; 4: 29.

24. Thimonier E, Guillaud O, Walter T, Decullier E, Vallin M, Boillot O, et al. Conversion to everolimus dramatically improves the prognosis of de novo malignancies after liver transplantation for alcoholic liver disease. Clin Transplant. 2014; 28: 1339-1348.

25. Cholongitas E, Mamou C, Rodriguez-Castro KI, Burra P. Mammalian target of rapamycin inhibitors are associated with lower rates of hepatocellular carcinoma recurrence after liver transplantation: A systematic review. Transpl Int. 2014; 27: 1039-1049.

26. Cheung $\mathrm{CY}, \mathrm{Ma} \mathrm{MK}$, Chak WL, Chau KF, Tang SC. Conversion to mammalian target of rapamycin inhibitors in kidney transplant recipients with de novo cancers. Oncotarget. 2017; 8: 4483344841.

27. Kirchner GI, Meier-Wiedenbach I, Manns MP. Clinical pharmacokinetics of everolimus. Clin Pharmacokinet. 2004; 43: 83-95.

28. Vinayak R, Cruz RJ, Jr., Ranganathan S, Mohanka R, Mazariegos G, Soltys K, et al. Pediatric liver transplantation for hepatocellular cancer and rare liver malignancies: US multicenter and singlecenter experience (1981-2015). Liver Transplant. 2017; 23: 1577-1588.

29. Sindhi R, Rohan V, Bukowinski A, Tadros S, de Ville de Goyet J, Rapkin L, et al. Liver transplantation for pediatric liver cancer. Cancers. 2020; 12: 720.

30. Pham TA, Gallo AM, Concepcion W, Esquivel CO, Bonham CA. Effect of liver transplant on longterm disease-free survival in children with hepatoblastoma and hepatocellular cancer. JAMA Surg. 2015; 150: 1150-1158.

31. Vivarelli M, Cucchetti A, La Barba G, Ravaioli M, Del Gaudio M, Lauro A, et al. Liver transplantation for hepatocellular carcinoma under calcineurin inhibitors: Reassessment of risk factors for tumor recurrence. Ann Surg. 2008; 248: 857-862.

32. Rodríguez-Perálvarez M, Tsochatzis E, Naveas MC, Pieri G, García-Caparrós C, O'Beirne J, et al. Reduced exposure to calcineurin inhibitors early after liver transplantation prevents recurrence of hepatocellular carcinoma. J Hepatol. 2013; 59: 1193-1199.

33. Rausch L, Koenecke C, Koch HF, Kaltenborn A, Emmanouilidis N, Pape L, et al. Matched-pair analysis: Identification of factors with independent influence on the development of PTLD after kidney or liver transplantation. Transplant Res. 2016; 5: 6.

34. Shapiro R, Scantlebury VP, Jordan ML, Vivas C, Tzakis AG, Ellis D, et al. FK506 in pediatric kidney transplantation--primary and rescue experience. Pediatr Nephrol. 1995; 9(Suppl): S43-S48. 
35. Shapiro R, Scantlebury VP, Jordan ML, Vivas C, Ellis D, Lombardozzi-Lane S, et al. Pediatric renal transplantation under tacrolimus-based immunosuppression. Transplantation. 1999; 67: 299303.

36. Kusuki S, Hashii Y, Fukushima N, Takizawa S, Tokimasa S, Kogaki S, et al. Pediatric post-transplant diffuse large B cell lymphoma after cardiac transplantation. Int J Hematol. 2009; 89: 209-213.

37. Jimenez-Rivera C, Avitzur Y, Fecteau AH, Jones N, Grant D, Ng VL. Sirolimus for pediatric liver transplant recipients with post-transplant lymphoproliferative disease and hepatoblastoma. Pediatr Transplant. 2004; 8: 243-248.

38. Al-Akash SI, Al Makadma AS, Al Omari MG. Rapid response to rituximab in a pediatric liver transplant recipient with post-transplant lymphoproliferative disease and maintenance with sirolimus monotherapy. Pediatr Transplant. 2005; 9: 249-253.

39. Gijsen VM, Hesselink DA, Croes K, Koren G, de Wildt SN. Prevalence of renal dysfunction in tacrolimus-treated pediatric transplant recipients: A systematic review. Pediatr Transplant. 2013; 17: 205-215.

40. Brinkert F, Kemper MJ, Briem-Richter A, van Husen M, Treszl A, Ganschow R. High prevalence of renal dysfunction in children after liver transplantation: Non-invasive diagnosis using a cystatin C-based equation. Nephrol Dial Transplant. 2011; 26: 1407-1412.

41. Pape L, Offner G, Kreuzer M, Froede K, Drube J, Kanzelmeyer N, et al. De novo therapy with everolimus, low-dose ciclosporine $A$, basiliximab and steroid elimination in pediatric kidney transplantation. Am J Transplant. 2010; 10: 2349-2354.

42. Hocker B, Feneberg R, Kopf S, Weber LT, Waldherr R, Wuhl E, et al. SRL-based immunosuppression vs. CNI minimization in pediatric renal transplant recipients with chronic CNI nephrotoxicity. Pediatr Transplant. 2006; 10: 593-601.

43. Casas-Melley AT, Falkenstein KP, Flynn LM, Ziegler VL, Dunn SP. Improvement in renal function and rejection control in pediatric liver transplant recipients with the introduction of sirolimus. Pediatr Transplant. 2004; 8: 362-366.

44. Levitsky J, O'Leary JG, Asrani S, Sharma P, Fung J, Wiseman A, et al. Protecting the kidney in liver transplant recipients: Practice-based recommendations from the American society of transplantation liver and intestine community of practice. Am J Transplant. 2016; 16: 2532-2544.

45. Grushkin C, Mahan JD, Mange KC, Hexham JM, Ettenger R. De novo therapy with everolimus and reduced-exposure cyclosporine following pediatric kidney transplantation: A prospective, multicenter, 12-month study. Pediatr Transplant. 2013; 17: 237-243.

46. Masetti M, Montalti R, Rompianesi G, Codeluppi M, Gerring R, Romano A, et al. Early withdrawal of calcineurin inhibitors and everolimus monotherapy in de novo liver transplant recipients preserves renal function. Am J Transplant. 2010; 10: 2252-2262.

47. Saliba F, De Simone P, Nevens F, De Carlis L, Metselaar HJ, Beckebaum S, et al. Renal function at two years in liver transplant patients receiving everolimus: Results of a randomized, multicenter study. Am J Transplant. 2013; 13: 1734-1745. 


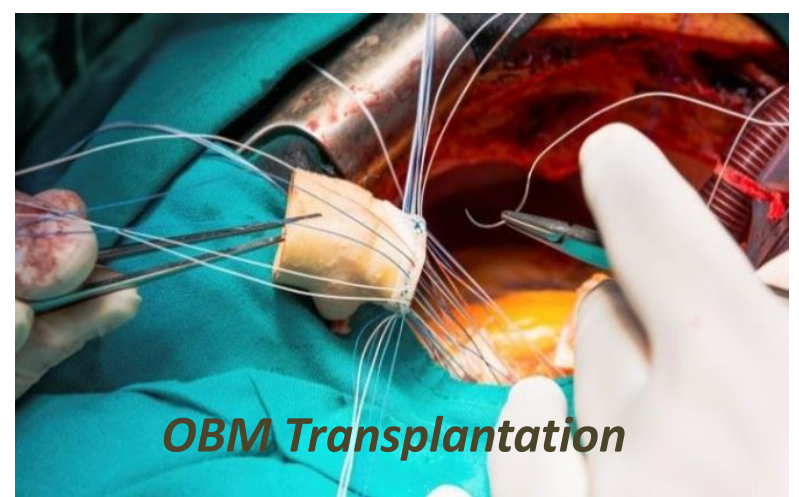

Enjoy OBM Transplantation by:

1. Submitting a manuscript

2. Joining in volunteer reviewer bank

3. Joining Editorial Board

4. Guest editing a special issue

For more details, please visit:

http://www.lidsen.com/journals/transplantation 